\title{
Impact of differential cyclin DI expression and localisation in prostate cancer
}

\author{
CES Comstock', MP Revelo², CR Buncher ${ }^{3}$ and KE Knudsen*,1,4,5 \\ 'Department of Cell and Cancer Biology, University of Cincinnati College of Medicine, Cincinnati, OH 45267, USA; '2Department of Pathology and \\ Laboratory Medicine, University of Cincinnati College of Medicine, Cincinnati, OH 45267, USA; ${ }^{3}$ Department of Environmental Health, University of \\ Cincinnati College of Medicine, Cincinnati, OH 45267, USA; ${ }^{4}$ Center for Environmental Genetics, University of Cincinnati College of Medicine, Cincinnati, \\ $\mathrm{OH}$ 45267, USA; ${ }^{5}$ University of Cincinnati Cancer Center, University of Cincinnati College of Medicine, Cincinnati, OH 45267, USA
}

Cyclin DI is a critical regulator of androgen-dependent transcription and cell cycle progression in prostate cancer cells. Despite the influence of D-type cyclins on prostate cancer proliferation, few studies have examined the expression of cyclin DI in localised tumours or challenged its relevance to disease progression. Cyclin DI status was characterised using immunohistochemistry in 38 non-neoplastic prostate samples, 138 primary human prostate carcinomas, and three lymph node metastatic specimens. Relevance of cyclin DI to preoperative prostate-specific antigen (PSA) levels, Ki-67 index, and p2 I Cipl status was also examined. Cyclin DIpositive phenotype was increased in primary carcinoma compared to non-neoplastic tissue, and was evident in all lymph node metastases cases. Interestingly, at least three distinct localisation patterns were observed in the cyclin DI-positive cohort, wherein cytoplasmic localisation was identified in a large fraction, and this pattern was predominant in lower grade tumours. Relevance of altered cyclin DI status was observed, wherein cyclin DI-positive tumours were associated with low preoperative PSA levels, consistent with in vitro reports that cyclin DI may alter the expression of this tumour marker. Moreover, tumours with predominantly cytoplasmic cyclin DI showed the lowest Ki-67 index, whereas nuclear cyclin DI was associated with higher grade, elevated Ki-67, and increased nuclear $\mathrm{p} 2 \mathrm{I}_{\mathrm{Cip}}$. These data demonstrate that differential cyclin DI status may influence clinicopathological parameters, and reveal new insight as to the regulation and potential consequence of cyclin DI expression in prostate cancer.

British Journal of Cancer (2007) 96, 970-979. doi:I0.1038/sj.bjc.66036I5 www.bjcancer.com

(c) 2007 Cancer Research UK

Keywords: prostate-specific antigen; Ki-67; p2I Cipl; cytoplasmic; proliferation; androgen receptor

Prostatic adenocarcinoma is the most commonly diagnosed malignancy in the US, and is a leading cause of cancer death in men (Jemal et al, 2006). This tumor type is dependent on androgen for growth and survival, and treatment for metastatic disease capitalises on this dependence. Androgen elicits its biologic effects through activation of the androgen receptor (AR), a liganddependent transcription factor that belongs to the nuclear receptor superfamily (Trapman, 2001; Asatiani and Gelmann, 2005; Gao et al, 2005). Upon ligand binding, activated AR stimulates a gene expression program that induces cellular proliferation. As such, first line therapy for disseminated prostate cancer entails ablation of AR activity, either through deprivation of ligand or through the use of direct AR antagonists (Sonpavde et al, 2006). These therapies are highly effective, and result in tumour cell death or cell cycle arrest (Agus et al, 1999). Moreover, therapeutic efficacy is clinically monitored by reductions in serum PSA (prostate specific

*Correspondence: Dr KE Knudsen, University of Cincinnati College of Medicine, Department of Cell and Cancer Biology, Vontz Center for Molecular Studies, 3125 Eden Ave., ML 052I, Cincinnati, OH 45267. 052I, USA.

E-mail: karen.knudsen@uc.edu

Received 28 September 2006; revised 3 January 2007; accepted 9 January 2007 antigen), as expression of PSA is dependent on AR activity in prostatic cells and correlates with tumour burden (Catalona and Loeb, 2005). Despite the initial success of therapy, recurrent tumours ultimately form wherein AR activity has been restored, and this event is typically preceded by a detectable rise in serum PSA (Feldman and Feldman, 2001). Restoration of AR activity is known to occur through several discrete pathways, and in model systems of prostate cancer reactivation of $\mathrm{AR}$ is causative for therapeutic relapse and tumour recurrence (Chen et al, 2004). Moreover, the majority of studies have shown that recurrent, androgen-independent prostate cancer cells still require AR activity for proliferation and survival (Taplin and Balk, 2004; Haag et al, 2005).

Given the importance of androgen action and AR function in prostate cancer growth and progression, much emphasis has been devoted to delineating the mechanisms by which AR promotes tumour cell proliferation and the factors that govern these events. Toward this end, we and others have shown that as part of its proproliferative program, androgen induces accumulation of Dtype cyclins (Knudsen et al, 1998; Xu et al, 2006). This class of cyclins interact with and activate cyclin-dependent kinases (CDK) $4 / 6$ to promote $G_{1}$ progression during the cell cycle (Mittnacht, 1998; Sherr and Roberts, 2004). Recent studies have shown that AR stimulates cell cycle progression at least in part through induction of mTOR (mammalian Target of Rapamycin) activity, which 
facilitates cyclin D protein accumulation (Xu et al, 2006). Additional factors are also suspected to control this event, such as $\mathrm{p} 21^{\mathrm{Cip} 1}$, which is an essential accessory factor for the assembly, stabilisation, and translocation of active cyclin D1/CDK4 complexes to the nucleus (Cheng et al, 1999; Parry et al, 1999). Furthermore, p $21^{\mathrm{Cip} 1}$ protein levels are induced by androgen stimulation (Knudsen et al, 1998) and $\mathrm{p} 21^{\mathrm{Cip} 1}$ has been shown to be a direct AR target gene (Lu et al, 1999). Displacement of p $21^{\text {Cip1 }}$ from active cyclin D1/CDK4 complexes allows $\mathrm{p} 21^{\mathrm{Cip} 1}$ to bind and inhibit CDK2 activity, thereby inhibiting progression through $\mathrm{G}_{1}$ and into $S$ phase (Sherr and Roberts, 2004). Thus, the ability of cyclin D1 to interact with $\mathrm{p} 21^{\mathrm{Cip} 1}$ is thought to be a critical function in promoting cellular proliferation and is often associated with mitogenic stimulation (Alt et al, 2002).

In prostate cancer cells, it has been shown that cyclin D1 induction is insufficient to drive androgen-independent proliferation (Knudsen et al, 1998; Fribourg et al, 2000), and forced elevation of cyclin D1 in the presence of androgen suppresses rather than promotes cellular proliferation (Petre-Draviam et al, 2003). These effects are at least partially attributed to the ability of cyclin D1 to bind and inhibit AR activity (Knudsen et al, 1999; Reutens et al, 2001), as achieved through at least two discrete mechanisms. First, cyclin D1 binds an N-terminal region of AR that is required for docking to its $\mathrm{C}$ terminus upon ligand binding and suppresses the efficacy of this $\mathrm{N}-\mathrm{C}$ interaction (Burd et al, 2005). Second, cyclin D1 can associate with histone deacetylases to repress transcription, and this function of cyclin D1 is essential for its AR corepressor activity (Lin et al, 2002; Petre-Draviam et al, 2005). Cyclin D1 can also bind to and modulate other transcription factors by similar mechanisms, with the largest class of proteins belonging to the nuclear receptor superfamily (Coqueret, 2002; Ewen and Lamb, 2004; Fu et al, 2004). These collective observations have culminated in a model whereby androgen-mediated induction of cyclin D1 serves to activate $\mathrm{CDK} 4$ and promote cell cycle progression, but that accumulated cyclin D1 engages in a negative feedback loop to limit or modulate the response to androgen stimulation. In the prostate, it is proposed that cyclin D1 acts as a rheostat to control the strength and duration of androgen stimulation and AR activity.

Despite the importance of cyclin D1 in eliciting and modulating the androgen response in prostate cancer, few studies have examined the expression profile of this protein in localised tumours or evaluated its relevance for disease progression. We examined 138 human radical prostatectomy samples for cyclin D1 expression, as compared to normal prostatic epithelia. We show that whereas cyclin D1 expression is low or absent in nonneoplastic tissue, its levels are increased in the majority of localised tumours. Surprisingly, four distinct expression profiles were observed in these tumour sets, wherein a large fraction of cyclin D1-positive tumours showed cytoplasmic restriction. Expression profiles showed some grade specificity, wherein nuclear cyclin D1 staining emerged almost exclusively in the higher grade tumours. Additionally, PSA expression was lower in the cyclin D1-positive tumours, indicating that cyclin D1 status may affect expression of serum markers that are dependent on AR activity. The relevance of cyclin D1 status to the proliferative index was also considered, wherein tumours with predominantly cytoplasmic cyclin D1 exhibited the lowest proliferative index, even as compared to cyclin D1-negative tumours. Lastly, nuclear p $21^{\mathrm{Cip} 1}$ status was investigated, and p $21^{\mathrm{Cip} 1}$ levels frequently associated with a more proliferative and predominantly nuclear cyclin D1 phenotype. Together, the data herein is the first to demonstrate that cyclin D1 can be differentially expressed in prostate cancer, and that the status and/or localisation of cyclin D1 expression are associated with meaningful changes in tumour marker expression and proliferative indices.

\section{MATERIALS AND METHODS}

\section{Tissue procurement}

Formalin-fixed paraffin-embedded serial sections $(5 \mu \mathrm{m})$ were obtained from 36 patients that were diagnosed with prostate cancer and underwent radical prostatectomy at the University of Cincinnati Hospital between 2000 and 2004 in accordance with institutional review board standards. Adjacent, non-neoplastic tissue was associated with 23 samples and preoperative PSA values were available for 20 patients. Additionally, three separate lymph node samples with metastatic prostate cancer were obtained. Human prostate tissue microarray slides containing individual tumour cores $(1.5 \mathrm{~mm}$ diameter, $5 \mu \mathrm{m})$ were purchased. One array (TA1) contained 80 cores (PR801; US Biomax, Ijamsville, MD, USA), whereas the other array (TA2) contained 49 cores with ninematched normal tissue and 35 associated PSA values (IMH-303; Imgenex, San Diego, CA, USA). All patient tumours and tissue microarrays were evaluated and graded by a pathologist according to established guidelines (Epstein et al, 2006).

\section{Immunohistochemistry}

Immunohistochemical staining for cyclin D1 and Ki-67 was performed using a BenchMark automated stainer (Ventana, Tucson, AZ, USA) using the avidin-biotin peroxidase technique following standard protocols. Staining for cyclin D1 was performed, on all samples, according to manufacturer specifications (P2D11F11; Ventana, Tucson, AZ). Staining for Ki-67 (1:25, MIB-1; DAKO, Carpinteria, CA, USA) was performed using a subset of 22 samples from the 36 patient samples and one tissue microarray (TA1). Positive and negative controls for both antibodies gave the expected results. Immunohistochemistry for p2 $1^{\text {Cip } 1}$ ( $1: 1000$, SC-397; Santa Cruz, CA, USA) and AR (1:5000, SC-816; Santa Cruz, CA, USA) was performed using a Vectastain Elite $A B C$ rabbit staining kit according to manufacturer specifications (Vector Laboratories, Inc., Burlingame, CA, USA). Briefly, a subset of 16 patient samples and all three lymph node metastatic samples were de-paraffinised in xylene and rehydrated to $70 \%$ ethanol. Antigen retrieval was achieved in a $600 \mathrm{~W}$ microwave using an antigen unmasking solution (Vector Laboratories, Inc., Burlingame, CA, USA). Following staining, the antigen was visualised using diaminobenzidine substrate for peroxidase using a 2 min development (DAKO, Carpinteria, CA, USA) and counterstained with haematoxylin.

\section{Scoring and statistical analysis}

Nuclear and cytoplasmic cyclin D1 staining intensity was assessed before the clinical parameters (MPR) and semi-quantitatively scored as 0 (absent), 1- (weak/focal $<10 \%$ of sample), $1+$ (weak intensity $<25 \%$ of sample), $2+$ (moderate intensity $25-50 \%$ of sample), or $3+$ (strong intensity $>50 \%$ of sample). The percentage of nuclear $\mathrm{Ki}-67$ and p21 ${ }^{\mathrm{Cip} 1}$ were counted without knowledge of the clinical data, using a $10 \times 10$ grid eyepiece at $\times 20$ magnification. Prostate and metastatic tumour samples were assessed by counting nine separate fields, whereas only five separate fields could be counted for each tumour core on the microarray. Approximately 600 cells were counted in each field. The data were plotted by Graph Pad Prism (v4.0) using the mean \pm standard error (s.e.m.) or by scatter plot with the mean value. Statistical analysis was also performed and correlations were determined by linear regression. Significant differences $(P<0.05)$ between multiple groups were determined by one-way analysis of variance using Kruskal - Wallis with a Dunn's multiple comparison post hoc test of all pairwise comparisons, or by two-tailed $t$-test for two group comparisons. 


\section{RESULTS}

\section{Disparate localisation of cyclin D1 is associated with prostate tumour grade}

To dissect the expression patterns of cyclin D1 in prostate cancer, an initial cohort of 36 human primary prostate adenocarcinomas was examined by immunohistochemistry. Of these, matched nonneoplastic adjacent tissues were available for 23 specimens. The Gleason and cyclin D1 scores were assessed for each patient specimen (Figure 1A). In agreement with the literature (Han et al,
1998; Aaltomaa et al, 1999; Murphy et al, 2005), cyclin D1 was absent in the majority of non-neoplastic prostate tissue (20/23) and of the three positive cases one exhibited weak/focal staining. These data are consistent with the low proliferative index of adult prostatic epithelia. Interestingly, of the cyclin D1-positive tumours (34/36), disparate cyclin D1 staining was observed in the tumour regions. Staining was confined to the epithelial-derived tumour cells, and stromal regions were negative in all cases. At least four distinct cyclin D1 expression patterns were identified (Figure 1B). First, the majority of tumours scored high for cytoplasmic cyclin D1 with little or no nuclear cyclin D1 reactivity (25/36). Second, a
A

\begin{tabular}{|c|c|c|c|c|}
\hline \multirow[b]{2}{*}{ Tumour } & \multirow[b]{2}{*}{ Gleason } & \multicolumn{3}{|c|}{ Cyclin D1 score } \\
\hline & & Nuclear & Cytoplasmic & $\begin{array}{c}{ }^{\uparrow} \text { Non- } \\
\text { neoplastic }\end{array}$ \\
\hline 01 & 5 & 0 & 0 & $2+$ \\
\hline 02 & 6 & 0 & $1-$ & NA \\
\hline 03 & 6 & 0 & $1-$ & 0 \\
\hline 04 & 6 & 0 & $1-$ & 0 \\
\hline 05 & 6 & 0 & 1 & 0 \\
\hline 06 & 6 & 0 & $1+$ & NA \\
\hline 07 & 6 & 0 & $2+$ & NA \\
\hline 08 & 6 & 0 & $2+$ & NA \\
\hline 09 & 6 & 0 & $2+$ & NA \\
\hline 10 & 6 & 0 & $2+$ & 0 \\
\hline 11 & 6 & 0 & $2+$ & 0 \\
\hline 12 & 6 & 0 & $2+$ & 0 \\
\hline 13 & 6 & 0 & $2+$ & 0 \\
\hline 14 & 6 & 0 & $2+$ & 0 \\
\hline 15 & 6 & 0 & $3+$ & NA \\
\hline 16 & 6 & 0 & $3+$ & 0 \\
\hline 17 & 6 & $2+$ & $1+$ & $1+$ \\
\hline 18 & 7 & 0 & $3+$ & NA \\
\hline 19 & 7 & 0 & $3+$ & NA \\
\hline 20 & 7 & 0 & $3+$ & W/F \\
\hline 21 & 7 & $1+$ & $1-$ & 0 \\
\hline 22 & 7 & $1+$ & $1+$ & NA \\
\hline 23 & 7 & $2+$ & $1+$ & 0 \\
\hline 24 & 7 & $2+$ & $2+$ & 0 \\
\hline 25 & 7 & $2+$ & $3+$ & 0 \\
\hline 26 & 8 & 0 & 0 & 0 \\
\hline 27 & 8 & 0 & $1+$ & NA \\
\hline 28 & 8 & $1+$ & $2+$ & 0 \\
\hline 29 & 8 & $2+$ & $1+$ & NA \\
\hline 30 & 8 & $2+$ & $3+$ & 0 \\
\hline 31 & 8 & $2+$ & $3+$ & 0 \\
\hline 32 & 9 & 0 & 1 & 0 \\
\hline 33 & 9 & 0 & $3+$ & NA \\
\hline 34 & 9 & $3+$ & $1+$ & NA \\
\hline 35 & 9 & $3+$ & $3+$ & 0 \\
\hline 36 & 9 & $3+$ & $3+$ & 0 \\
\hline
\end{tabular}

${ }^{\uparrow}$ Matched non-neoplastic;

$\mathrm{NA}=$ not available; $\mathrm{W} / \mathrm{F}=$ weak/focal staining.
B

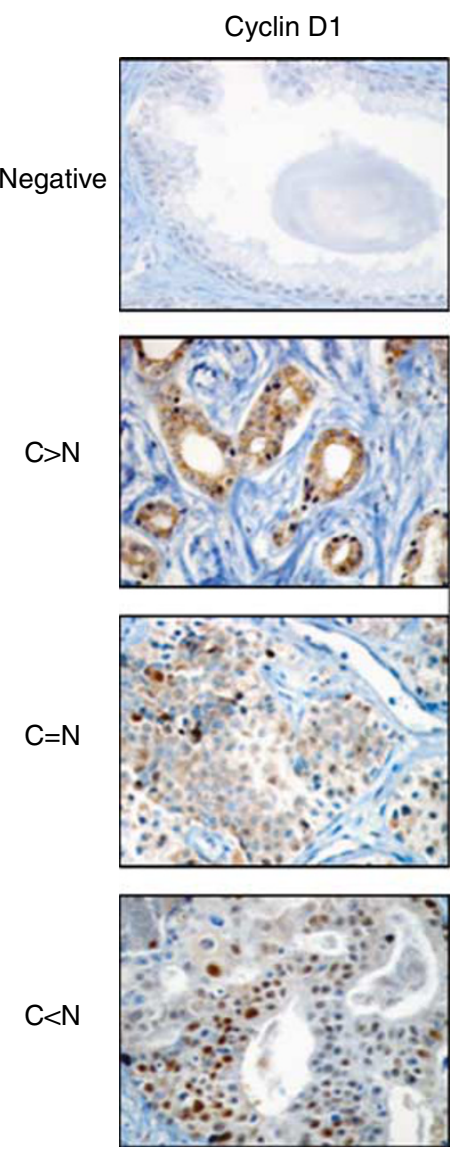

C

Cyclin D1

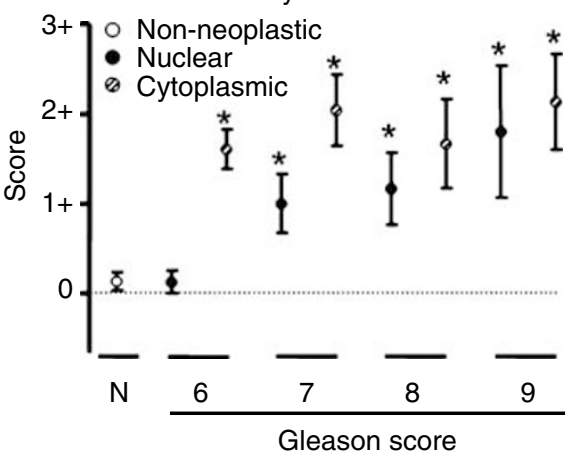

Figure I Disparate localisation of cyclin DI in localised prostate carcinoma is tumour grade specific. (A). Summary of cyclin DI immunohistochemistry in human primary prostate tumours $(n=36)$. Tumours are grouped according to Gleason and cyclin DI scores. (B). Representative cyclin DI immunohistochemical images ( $\times 40$ magnification) from primary prostate tumours displaying four different localisation patterns: negative, higher cytoplasmic than nuclear $(C>N)$, cytoplasmic equal to nuclear $(C=N)$, and higher nuclear than cytoplasmic $(C<N)$. $(\mathbf{C})$. Non-neoplastic $(O)$, nuclear $(\mathbf{O})$, and cytoplasmic (囚) cyclin DI scores for each Gleason grade were averaged from Figure IA, and presented as mean \pm s.e.m. Only values with more than one determination are shown. Statistical differences from non-neoplastic are indicated (*) and described in the Results section. 
minority of tumours showed predominately nuclear cyclin D1 (5/36). Third, a similar number of cases showed equivalent cyclin D1 staining in both the nuclear and cytoplasmic compartments (4/36). The fourth pattern was represented by those tumours devoid of cyclin D1 (2/36). These data are consistent with the in vitro observations that cyclin D1 can be stringently regulated as a function of subcellular localisation (Alt et al, 2000; Radu et al, 2003) and reveal that distinct localisation patterns are observed in prostate cancer.

Previous studies have shown that cyclin D1 activity is strongly influenced by its subcellular localisation (Diehl and Sherr, 1997; Barr and Johnson, 2001; Lin and Gelman, 2002; Balasenthil et al, 2004; Alao et al, 2006; Sumrejkanchanakij et al, 2006). Given the distinct patterns of localisation observed in the initial cohort of prostatectomy specimens, the prevalence of cyclin D1 staining patterns was examined as a function of tumour grade. Cytoplasmic cyclin D1 staining was significantly increased in tumours compared to non-neoplastic tissue $(\mathrm{p}<0.05)$ and appeared to be predominant in Gleason 6 and 7 tumours (Figure 1C). By contrast, nuclear cyclin D1 emerged in higher grade tumours (Gleason 8 and 9) and was also accompanied by high cytoplasmic cyclin D1 staining. Importantly, a positive linear association between Gleason score and nuclear cyclin D1 was observed $(P<0.01)$. These data indicate that disparate cyclin D1 staining patterns correlated with specific tumour grades.

To challenge further these observations, the initial cohort was expanded to include two different human prostate carcinoma tissue microarrays (Table 1, TA1 and TA2). For clarity, the cases

Table I Immunohistochemical summary of cyclin DI in tissue microarrays

\begin{tabular}{|c|c|c|c|c|c|}
\hline \multirow[b]{3}{*}{ Normal $^{c}$} & \multirow{3}{*}{$\begin{array}{l}n \\
15\end{array}$} & \multirow{3}{*}{$\begin{array}{c}\text { Cyclin DI negative } \\
\text { TAI, TA2 } \\
6,9\end{array}$} & \multicolumn{3}{|c|}{ Cyclin DI localisation } \\
\hline & & & $\mathbf{C}>\mathbf{N}^{\mathbf{a}}$ & $\mathbf{C}=\mathbf{N}$ & $\mathbf{C}<\mathbf{N}$ \\
\hline & & & - & - & - \\
\hline \multicolumn{6}{|l|}{$\begin{array}{l}\text { Tumour } \\
\text { Gleason }\end{array}$} \\
\hline 6 & 34 & $8,13(61.7)^{d}$ & ।, $3(\mid 1.8)$ & $4, \mid(\mid 4.7)$ & $2,2(11.8)$ \\
\hline 7 & 25 & $4,4(32.0)$ & $3,1(16.0)$ & $2,1(12.0)$ & $9,1(40.0)$ \\
\hline 8 & 33 & $9,4(39.4)$ & $2,2(12.1)$ & $2,1(9.10)$ & $13,0(39.4)$ \\
\hline 9 & 4 & $2,1(75.0)$ & - & - & $0,1(25.0)$ \\
\hline \multirow[t]{2}{*}{10} & 6 & 3,1 (66.7) & - & - & I, I (33.3) \\
\hline & 102 & $40,62.2^{\mathrm{e}}$ & $9.2,16.2$ & $12.3,8.1$ & $38.5,13.5$ \\
\hline
\end{tabular}

${ }^{a} \mathrm{C}=$ cytoplasmic, $\mathrm{N}=$ nuclear. ${ }^{\mathrm{b}}$ Number of cases separated by tissue microarrays

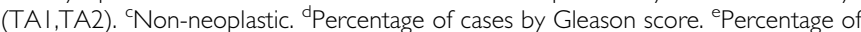
cases by individual tissue microarray. are presented separately by cohort and annotated by Gleason score and cyclin D1 localisation pattern. As shown, the four identified staining patterns observed in the initial cohort (Figure 1A) were also observed in each tissue microarray. As expected, all 15 nonneoplastic cases were cyclin D1-negative. Of the combined 102 tumour specimens, the largest fraction scored negative for cyclin $\mathrm{D} 1$ (40 and $62.2 \%$; TA1 and TA2, respectively) suggesting that cyclin D1 expression is not requisite for tumour maintenance. Cytoplasmic restriction of cyclin D1 staining was also observed (9.2 and $16.2 \%$, TA1 and TA2, respectively), and this class was associated with the lower Gleason scores. As in the initial cohort, tumours in the microarray with a high Gleason score maintained, cytoplasmic cyclin D1, but tended to be accompanied by higher nuclear cyclin D1. Combined, these data provide evidence that cyclin D1 expression is increased and shows distinct localisation patterns in localised disease, wherein these patterns are altered as a function of Gleason score.

\section{Cyclin D1 expression in metastatic prostate carcinoma}

The unique patterns of cyclin D1 in localised tumours prompted us to investigate cyclin D1 expression in metastatic tumours. For these studies, cyclin D1 localisation was evaluated in lymph node metastases obtained from three individual patients. Haematoxylin and eosin (H\&E) staining of all three cases revealed a similar morphology with densely packed and disorganised tumour cells and no glandular structure (Figure 2, left panel and data not shown). All three metastatic tumours stained nuclear positive for the AR, thus validating the tumour cells as prostatic in origin (Figure 2, middle panel and data not shown) Although the available sample size is small, all tumours exhibited exclusively modest $(1+)$ nuclear cyclin D1 staining (Figure 2, right panel and data not shown), whereas the surrounding stromal tissue was null for cyclin D1. These results suggest that cyclin D1 localization may be altered in lymph node metastases, wherein cyclin D1 expression is low and confined to the nucleus.

\section{Cyclin D1 status is inversely associated with PSA levels}

Cyclin D1 has the potential to regulate both cellular proliferation and AR-dependent transcription in prostate cancer cells (Burd et al, 2006a). Therefore, a link between the expression of cyclin D1 and PSA, an AR target gene, was examined. For these studies, the impact of cyclin D1 status on AR function was assessed using preoperative PSA levels. Of all the tumours examined, preoperative PSA levels were available for 53 patients. From the available specimens, $23(43.3 \%)$ were cyclin D1-negative and $30(56.6 \%)$ were cyclin D1-positive (Figure 3). As shown, the mean PSA value for the cyclin D1-positive group $\left(15.5 \pm 4.03 \mathrm{ng} \mathrm{ml}^{-1}\right)$ was significantly lower than the cyclin D1-negative group
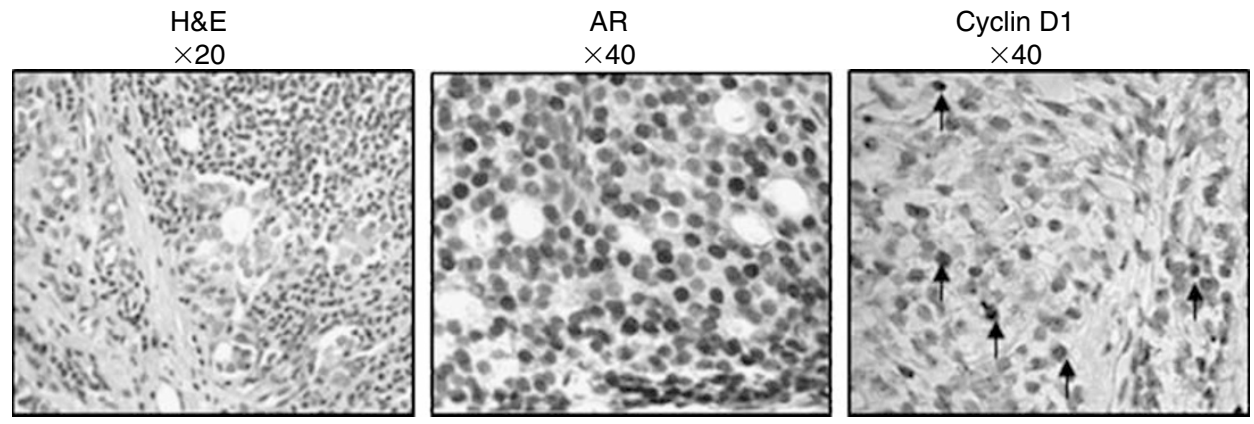

Figure 2 Cyclin DI expression in metastatic prostate carcinoma. Representative immunohistochemical images from prostate-derived lymph node metastatic tumours. Left panel: Haematoxylin and eosin staining showing disorganised architecture of the metastatic tumours. Middle panel: Strong nuclear positive AR staining in the majority of tumour cells. Right Panel). Low nuclear cyclin DI staining (score of I + ). Arrows indicate tumours cells with evident positive staining. Magnification: Left $(\mathrm{H} \& \mathrm{E}), \times 20$; middle and right (Haematoxylin counterstained), $\times 40$. 


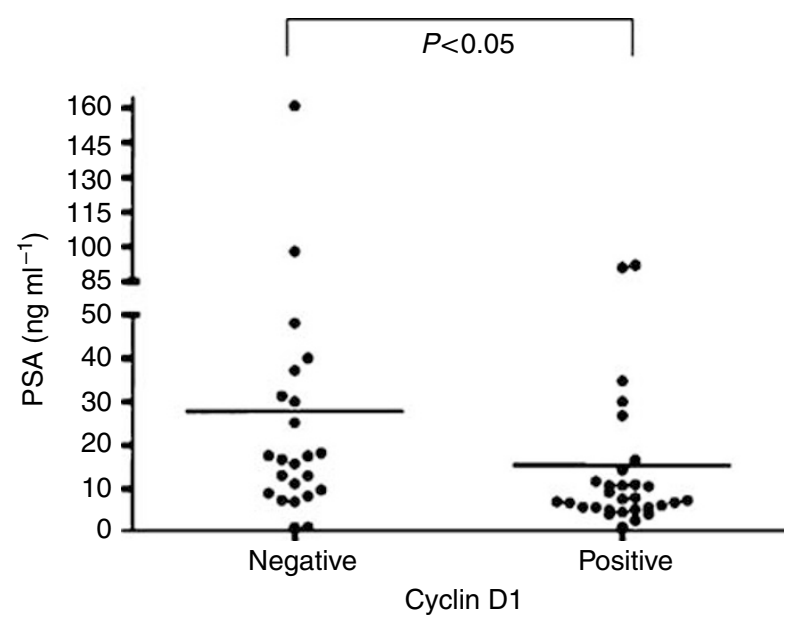

Figure 3 Cyclin DI status inversely associates with PSA levels. Combined preoperation PSA values $\left(\mathrm{ng} \mathrm{ml}^{-1}\right)$ separated as negative $(n=24)$ and positive $(n=29)$ for cyclin DI and presented as a scatter plot. Average preoperative PSA values for the cyclin DI-positive and -negative tumours were statistically different $(P<0.05)$. Average values for each group are described in the Results section.

$\left(27.7 \pm 7.43 \mathrm{ng} \mathrm{ml}^{-1}\right)(P<0.05)$. Unfortunately, there was insufficient statistical power to separate the PSA values according to cyclin D1 localisation or Gleason score (data not shown). However, these data are consistent with the established ability of cyclin D1 to suppress AR function and suggest that cyclin D1 status may influence factors relevant to prostate cancer diagnosis.

\section{Cyclin D1 localisation impacts proliferative status in prostate carcinoma}

The ability of cyclin D1 to control transcription factor activity is appreciated in a multitude of tissues. However, the canonical role of cyclin D1 is in its ability to promote cellular proliferation. The relevance of cyclin D1 localisation, in particular cytoplasmic localisation, to proliferative status has not been evaluated. To test this, representative tumours from each cyclin D1 staining category were processed to quantify the proliferative indices by Ki-67 immunoreactivity. Specific staining for Ki-67 was indicated by the absence of immunoreactivity in the adjacent matched-normal tissue or in the stromal regions. The raw Ki-67 data with representative images are provided in Figure 4A, and grouped according to cyclin D1 localisation and Gleason score. A scatter analysis between Gleason score and $\mathrm{Ki}-67$ status was assessed in the patient tumours and tissue microarray, and regression analysis was similar for each group (data not shown). These data are consistent with previous reports (Baretton et al, 1999) and provided confidence in the combined dataset. As expected, a significant positive correlation between localised tumour score and proliferation was determined $(P<0.05)$, and the highest average proliferative index came from the metastatic tumours (Figure 4B). When the impact of cyclin D1 localisation on proliferation was examined (Figure 4C), a statistically significant $(P<0.01)$ difference was identified between predominately cytoplasmic cyclin D1 $(4.33 \pm 0.63)$ and predominately nuclear cyclin D1 $(12.5 \pm 2.77)$ tumours. The proliferative status of the cytoplasmic cyclin D1 tumours were typically lower than the cyclin D1-negative $(7.25 \pm 1.34)$ tumours, although this did not reach statistical significance. This potentially interesting observation may suggest that cytoplasmic localisation may play a role in suppressing cellular proliferation. Furthermore, these data support the role of nuclear cyclin D1 as an initiator of cell cycle progression, where it is able to bind and activate CDK. However, it should be noted that a number of cyclin D1-positive tumours in all three localisation groups had a low proliferative index (Figure 4C), demonstrating that cyclin D1 expression itself is not sufficient to induce cellular proliferation.

\section{Contribution of $\mathrm{p}^{2} 1^{\mathrm{Cip} 1}$ to proliferation and progression of prostate carcinoma}

Although the mechanisms governing cyclin D1 localisation are not completely understood, p2 $1^{\text {Cip1 } 1}$ is a key modulator of both cyclin $\mathrm{D} 1$ activity and its subcellular localisation. Interaction of $\mathrm{p} 21^{\mathrm{Cip} 1}$ with cyclin D1/CDK is known to promote stabilisation and nuclear import of the complex, resulting in enhanced CDK activity (Parry et al, 1999; Gladden and Diehl, 2005). Similarly, p21 ${ }^{\text {Cip1 }}$ has been shown to be increased in prostate cancer and holds potential merit as a prognostic indicator (Matsushima et al, 1998; Sarkar et al, 1999; Omar et al, 2001; Rigaud et al, 2004). To determine the relevance of $\mathrm{p} 21^{\mathrm{Cip} 1}$ to cyclin D1 localisation and proliferation, p $21^{\text {Cip1 }}$ immunoreactivity was assessed in a subset of patient tumours $(n=16)$ and the three metastatic tumours wherein cyclin D1 and Ki-67 status had been determined. All three metastatic tumours and 11 of the 16 primary tumours $(68.8 \%)$ were p $21^{\text {Cip1 }}$ positive. The range of $\mathrm{p} 21^{\mathrm{Cip} 1}$ staining was between $1.41-12.9 \%$ of the tumour specimens. A positive trend was observed between tumour grade and nuclear p21 $1^{\mathrm{Cip} 1}$, but these data did not reach statistical significance (Figure 5A). However, a significant positive correlation was identified between nuclear p21 ${ }^{\mathrm{Cip} 1}$ and Ki-67 with an $r^{2}$ of 0.72 (Figure 5B). Separation by cyclin D1 localisation indicated that samples with higher nuclear cyclin D1 are likely to have higher nuclear $\mathrm{p} 21^{\mathrm{Cip} 1}$ (Figure $5 \mathrm{C}$ ), as the mean percent nuclear p $21^{\mathrm{Cip} 1}$ for the cyclin D1 groups were: $\mathrm{C}>\mathrm{N}(2.04 \pm 0.57)$, $\mathrm{C}=\mathrm{N}(2.53 \pm 1.71)$, and $\mathrm{C}<\mathrm{N}(8.99 \pm 3.91)$. However, no obvious trends were identified between $\mathrm{p} 21^{\mathrm{Cip} 1}$ and PSA or Gleason score (data not shown). Together, these data suggest that $\mathrm{p} 21^{\mathrm{Cip} 1}$ levels likely contribute more towards nuclear than cytoplasmic localisation of cyclin D1, and that increased nuclear p21 ${ }^{\mathrm{Cip} 1}$ levels may be associated with a more proliferative or advanced disease.

\section{DISCUSSION}

It has been previously shown through in vitro studies that cyclin D1 can influence androgen-dependent prostate cancer cell proliferation through its dual ability to modulate both CDK4 and AR activity (Petre-Draviam et al, 2005; Burd et al, 2006a). To elucidate further the role of cyclin D1 in prostate cancer, primary human prostate cancer specimens were utilised to assess the influence of cyclin D1 expression and localisation on PSA levels and proliferation index. The present findings demonstrate that cyclin D1 expression is enhanced in the majority of localised tumours as compared to non-neoplastic epithelia, thus indicating that cyclin D1 is aberrantly regulated in prostate cancer. Remarkably, cyclin D1-positive tumours displayed distinct localisation patterns, wherein tumours frequently exhibited predominately cytoplasmic cyclin D1. Investigations to challenge the impact of cyclin D1 expression revealed that cyclin D1-positive tumours associated with significantly lower preoperative PSA values, indicating that cyclin D1 status may influence tumour marker expression. Furthermore, there was a trend for tumours with predominately cytoplasmic cyclin D1 to harbour low proliferative potential as compared to tumours with predominately nuclear cyclin D1. Finally, expression of nuclear p21 $1^{\mathrm{Cip} 1}$, an important mediator of cyclin D1 action, correlated with proliferation and was associated with predominately nuclear cyclin D1, thus providing a potential mechanism for the differential localisation patterns of cyclin D1. Combined, these data suggest that cyclin D1 expression and localisation may influence proliferation and diagnostic factors in prostate cancer. 
A $\mathrm{Ki}-67$ in prostate tumours and metastasis
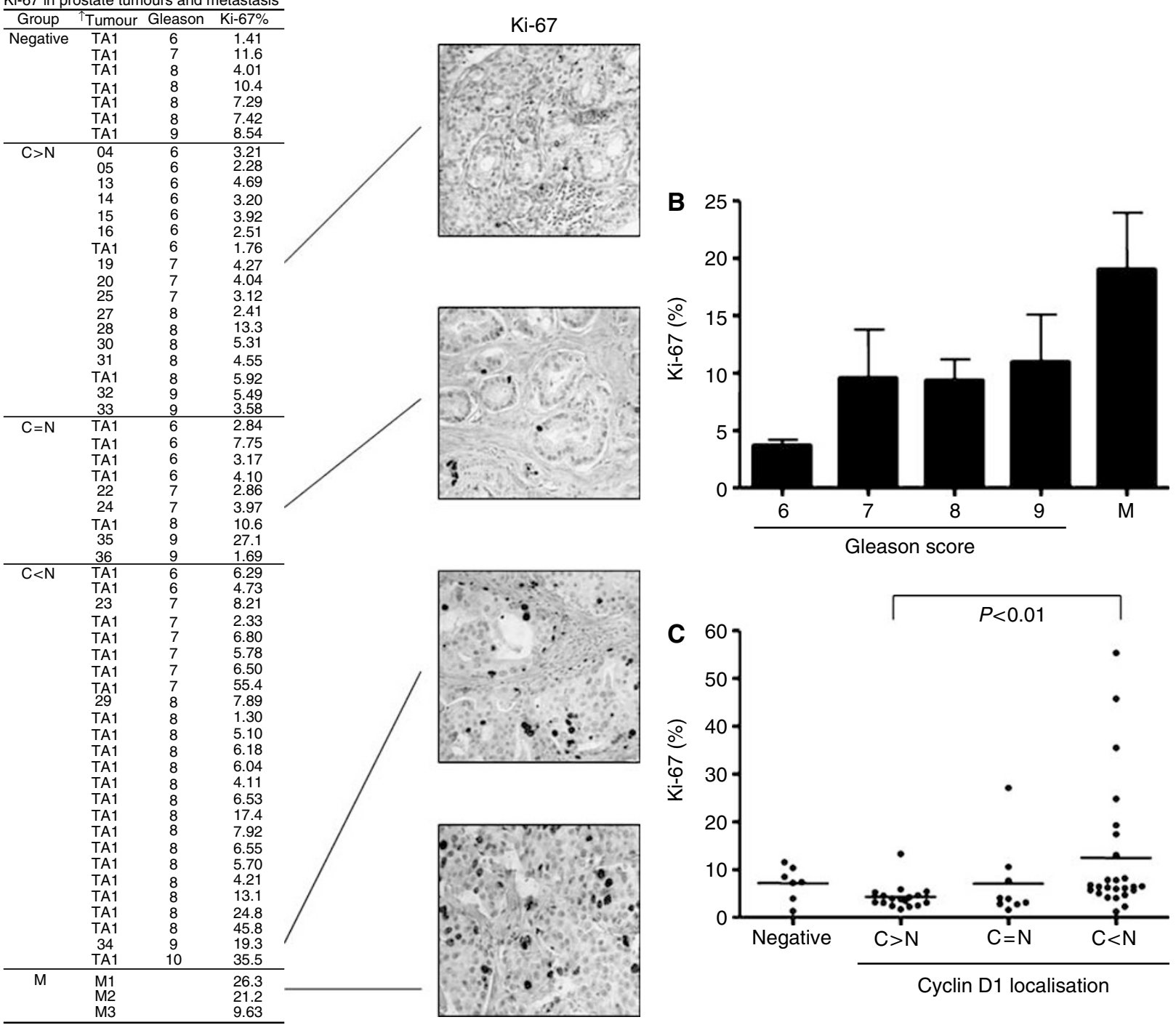

from tissue microarray 1 , patient tumours

(Table 1), and metastatic tumours.

Figure 4 Cyclin DI status impacts proliferation in prostate carcinoma. (A) Summary of nuclear Ki-67 (\%) immunohistochemistry for a subset of patient tumours $(n=22)$, a tissue microarray (TAI, $n=36)$, and the metastatic tumours $(n=3)$. Tumours are grouped according to cyclin DI localisation as described in Figure IB and ranked by Gleason grade. (B) Histograph of Ki-67 (\%) as a function of tumour progression $(n=22)$; the data (Mean + s.e.m.) were derived from Figure IA. A positive correlation between tumour progression and Ki-67 (\%) was seen $(P<0.05)$. (C) Ki-67 (\%) were separated according to cyclin DI localisation and presented as a scatter plot. Note: A number of DI-positive tumours in all the three localisation groups demonstrated low proliferation. The average Ki-67 (\%) for $C>N$ was statistically different than $C<N(P<0.01)$. Average values for each group are described in the Results section.

Few studies have addressed cyclin D1 expression or localisation in primary prostatic adenocarcinomas, and the criteria used to establish positive cyclin D1 staining have been divergent. The majority of studies have focused largely on nuclear cyclin D1, but common conclusions have failed to emerge. For example, using a staining cutoff of $>10 \%$, a trend for increased nuclear cyclin D1 with high Gleason scores $(\geqslant 7)$ was observed but not considered significant (Kallakury et al, 1997). A separate study, using a low $(<20 \%)-v s$ - high $(>20 \%)$ nuclear cyclin D1 staining criteria, reported only $12 \%$ of primary tumours with high cyclin D1 (Drobnjak et al, 2000). In the present analyses, quantification of all cyclin D1 localisation patterns was considered. Using this inclusive approach, $63 \%$ of tumours and only $8 \%$ of normal epithelia scored positive for cyclin D1 (Table 1), indicating that the protein is accumulated in prostate cancer. These data are congruent with a large study of 187 tumours, wherein $71 \%$ were scored cyclin D1- positive, with some cytoplasmic cyclin D1 noted but not quantified (Aaltomaa et al, 1999). Here, nuclear cyclin D1 correlated with Gleason score and proliferation, as is also consistent with our results (Figures $1 \mathrm{C}$ and $4 \mathrm{C}$, respectively). A series of smaller studies have also reported cyclin D1 induction in tumours compared to normal specimens (Han et al, 1998; Kolar et al, 2000; Murphy et al, 2005) and at least one of these considered all cyclin D1 localisations (including cytoplasmic and perinuclear) as positive, although correlates according to localisation were not considered (Han et al, 1998). Thus, the data herein confirm that increased cyclin D1 is seen with high frequency in prostate cancer, and is the first to provide a detailed assessment of cyclin D1 localisation patterns and correlates in organ-confined disease.

The impact of cyclin D1 localisation patterns in metastatic disease is less certain. This study examined only three prostatederived metastatic tumours, all of which showed low nuclear cyclin 

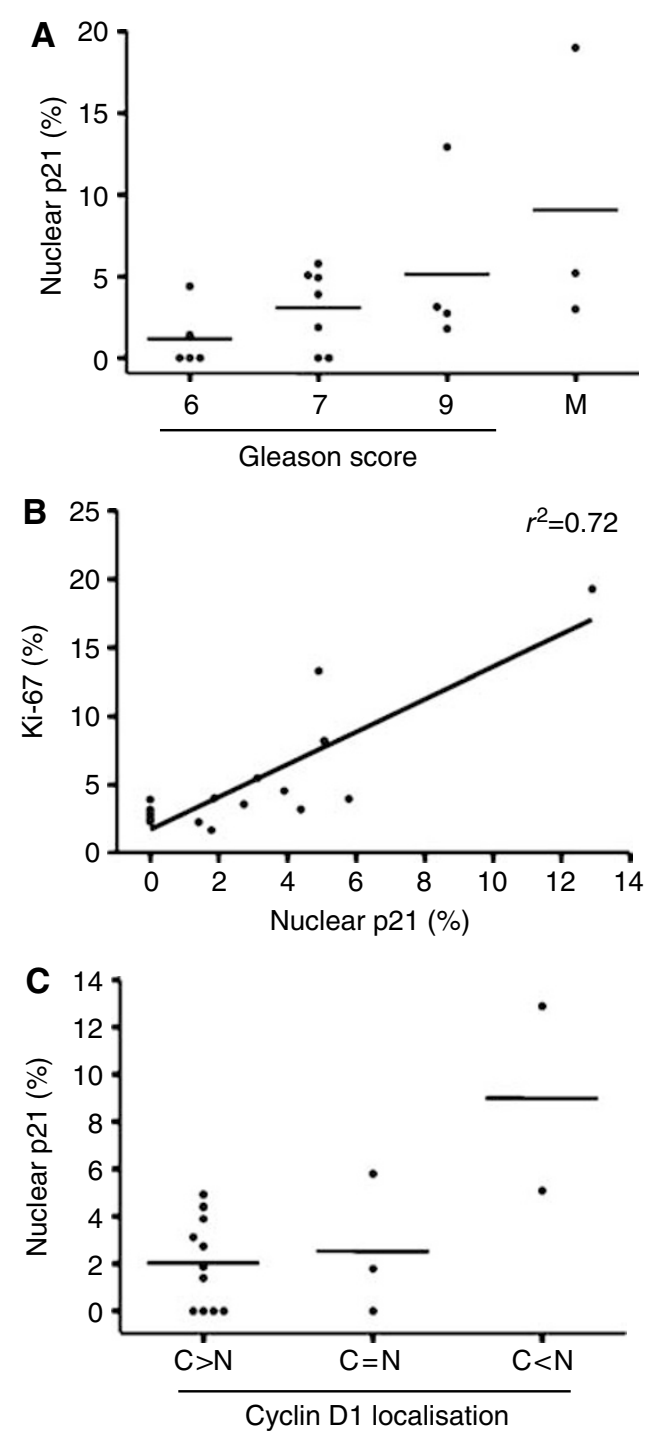

Figure 5 Contribution of $\mathrm{p}_{2} \mathrm{I}^{\mathrm{Cip} /}$ expression in prostate carcinoma Scatter plots characterising nuclear p2 $\left.\right|^{\mathrm{Cip} I}(\%)$ in a subset of patient tumours (PTI, $n=16$ ), which had been immunostained for cyclin DI and $\mathrm{Ki}$-67. (A) A trend between increased nuclear $\mathrm{p} 2 \mathrm{I}^{\mathrm{Cipl}}$ and Gleason score was observed. (B) A positive correlation by linear regression was identified between increased nuclear p2I Cipl and Ki-67 (\%) $\left(r^{2}=0.72\right)$. (C) Tumours with more nuclear DI appear to have more nuclear p2I Cip?. Average values for panels $A$ and $C$ are described in the Results section.

D1 staining and lacked cytoplasmic staining (Figure 2). Consistent with these results, previously reported data have shown that $84 \%$ of lymph node metastases lack significant cyclin D1 staining (Kallakury et al, 1997). In contrast, a second study assessed nuclear cyclin D1 in bone metastatic tumours and determined that a large fraction $(68 \%)$ of these specimens contained cyclin D1 (Drobnjak et al, 2000). These data suggest that cyclin D1 may hold a more pronounced role for proliferation in bone metastases compared to lymph node deposits. Consistent with a role for cyclin D1 in the proliferation of bone metastatic tumours from prostate, others have reported correlations between metastatic cyclin D1 expression derived from other tumour types (Chhieng et al, 1998). Given these observations, the concept that cyclin D1 prevalence and localisation may vary depending on metastatic site is intriguing and should be more rigorously considered.

Regardless of the site, the mechanism(s) by which cyclin D1 accumulates in prostate cancer cells remains to be discerned.

Cyclin D1 levels are typically under stringent regulation, but aberrant cyclin D1 expression has been implicated as having oncogenic properties in many neoplasias including breast (Arnold and Papanikolaou, 2005), pituitary (Faglia and Spada, 2001), and squamous cell carcinoma (Nadal and Cardesa, 2003). Overexpression of cyclin D1 may occur through multiple mechanisms, including chromosomal translocation events (e.g. Mantle cell lymphomas (Bigoni et al, 1996)), gene amplification (common in breast (Buckley et al, 1993) and oesophageal cancers (Jiang et al, 1993)), and defects in protein processing or transport (Gladden and Diehl, 2005). The propensity of selected tumour types to induce cyclin D1 accumulation in cancer may therefore be a heterogenous and complex event that culminates in a similar phenotype. Although genetic abnormalities in prostate cancer have been reported for other important cell cycle regulators such as phosphatase and tensin homologue (Majumder and Sellers, 2005), the retinoblastoma tumour suppressor protein (RB), and p53 (MacGrogan and Bookstein, 1997), perturbations in cyclin D1 appear to be less common. For example, cyclin D1 gene amplification did not increase in benign prostatic hyperplasia (BPH) or primary and refractory tumours of the prostate (Linja et al, 2004). Similarly, others have shown low cyclin D1 gene amplification (4\%) in primary prostate tumours (Gumbiner et al, 1999) and, depending on the method of detection, 5-15\% gene amplification in advanced prostate tumours (Bubendorf et al, 1999; El Gedaily et al, 2001). Thus, it is unlikely that the induction of cyclin D1 observed herein is a result of gene amplification. Recent studies in prostate cancer model systems have shown that cyclin D1 accumulates after androgen stimulation as a result of mTOR activation and resultant enhancement of cyclin D1 mRNA translation (Xu et al, 2006). However, the mechanisms underlying androgen-mediated mTOR induction remain elusive. Future studies directed at delineating mTOR activation may assist in revealing the mechanism(s) by which cyclin D1 accumulates in prostate cancer.

Once cyclin D1 protein accumulates, it is often regulated by subcellular localisation and proteasome-dependent degradation (Diehl et al, 1998; Germain et al, 2000). Our data indicate that this process, in part, is likely to be responsible for the disparate localisation of cyclin D1 in prostate cancer. The present finding that prostate cancer cells frequently exhibit cytoplasmic cyclin D1 is novel, but not without precedent. For example, elevated cyclin D1 with cytoplasmic cyclin D1 staining has been reported in many different tumour types, such as colorectal (Handa et al, 1999; Khor et al, 2006), pancreatic (Culhaci et al, 2005), lung (Dworakowska et al, 2005), thyroid (Temmim et al, 2006), and bladder (Sudo et al, 2003). Despite these observations only a handful of studies have addressed the functional consequence of cytoplasmic cyclin D1. It has been suggested that cytoplasmic cyclin D1 is more common in colorectal tumours deficient for $\beta$-catenin (Kuramochi et al, 2006); however, $\beta$-catenin has been shown to regulate cyclin D1 expression in colon cancer cells (Tetsu and McCormick, 1999). In pituitary (Hibberts et al, 1999; Simpson et al, 2001) and ovarian (Dhar et al, 1999) tumours, cytoplasmic cyclin D1 has been reported (35 and 59\% of cyclin D1-positive cases, respectively) but no correlations were identified. In hepatocellular carcinomas, cytoplasmic cyclin D1 appeared to significantly correlate with prognostic factors like intrahepatic metastasis (Sato et al, 1999). A large study which assessed cyclin D1 localisation was performed with 150 transitional cell carcinomas of the bladder, wherein cytoplasmic cyclin D1 increased with disease progression and correlated with decreased survival (Tut et al, 2001). This contrasts with our findings, wherein predominately cytoplasmic cyclin D1 correlated with lower Gleason scores (Figure 1C and Table 1) and exhibited the lowest proliferation index (Figure 4C). Furthermore, the proliferative index tended to be lower in the cytoplasmic cyclin D1 tumours than in the cyclin D1-deficient tumours. This observation suggests that restriction of cyclin D1 to the cytoplasm 
may allow suppression of cellular proliferation but requires a more rigorous investigation. Interestingly, a number of colorectal cancer studies have observed cytoplasmic cyclin D1 in tumour specimens (Palmqvist et al, 1998; Handa et al, 1999; McKay et al, 2000; Holland et al, 2001; Khor et al, 2006; Kuramochi et al, 2006) and at least one of these studies has reported that increased cytoplasmic cyclin D1 correlated with low proliferation (Palmqvist et al, 1998). This result is similar to our analyses (Figure 4C), wherein tumours with predominately cytoplasmic cyclin D1 showed a significantly lower proliferative index. In the case of prostate cancer, one mechanism could be through the ability to directly repress AR activity or sequester it from its nuclear targets. Alternatively, prostate cancer cells may have invoked mechanisms to bypass the cyclin D1 requirement (e.g. RB loss), thereby weakening the necessity to induce cyclin D1 accumulation (Lukas et al, 1995). However, it should be emphasised that our data also suggests that cyclin D1-positive status does not predict a high proliferative index (Figure 4C). Combined, these data support the contention that cyclin D1 is differentially localised in cancer, and that cytoplasmic cyclin D1 can correlate with proliferative outcomes in a tissue specific manner.

The emergence of nuclear cyclin D1 in the high Gleason scores is intriguing, and this localisation pattern correlated with a higher proliferative index. These observations are consistent with the ability of nuclear cyclin D1 to enhance CDK4 activity and promote $\mathrm{G}_{1}-\mathrm{S}$ progression. The delineation of the mechanism(s) by which nuclear emergence is facilitated will likely reveal new insights into advanced prostatic disease. One exciting possibility to be considered concerning nuclear cyclin D1 is the contribution of cyclin D1b, a splice variant of cyclin D1 that is restricted from nuclear export ( $\mathrm{Lu}$ et al, 2003). Attempts to develop a suitable cyclin D1b-specific antibody for immunohistochemistry have had limited success (data not shown). However, we have recently shown that cyclin D1b is upregulated in human prostate tumours, is selectively compromised for AR regulation, and may yield a specific growth advantage (Burd et al, 2006b). Therefore, future investigations will be directed at assessing cyclin D1b in tumours as a function of disease progression.

In addition to the effects on proliferation, previous data in prostate cancer cell lines suggest that cyclin D1 has specialised roles concerning AR function in the control of prostate cancer cellular function. Supporting this view, the present analyses revealed that cyclin D1 status can significantly correlate with serum PSA levels (Figure 3). Specifically, cyclin D1-positive tumours were more likely to be derived from patients with lower preoperative PSA values, perhaps reflective of the established ability of cyclin D1 to modulate AR function. This contention is consistent with previous reports, which observed a correlation between low cyclin D1 and elevated preoperation PSA values ( $>10 \mathrm{ng} \mathrm{ml}^{-1}$ ) (Drobnjak et al, 2000). On the basis of the PSA and proliferation data obtained in our study, it is conceivable that a subset of cyclin D1-positive tumours may exist that have increased proliferation and have low PSA values. The mechanism(s) and consequences of this observation will be of significant clinical interest, as these data indicate that cyclin D1 status may suppress tumour marker expression. Moreover, these data highlight the need to consider the effects, mediated by regulatory elements of proliferation (i.e. cyclin D1), on tumour marker expression.

As these collective findings indicated that cyclin D1 status and localisation patterns may impinge upon critical parameters, potential mechanism(s) underlying the differential cyclin D1 patterns were investigated. Here we show that $\mathrm{p} 21^{\mathrm{Cip} 1}$, which has been shown to positively regulate cyclin D1 accumulation, nuclear translocation, and CDK4 activation, is likely to contribute to the differential patterns observed. Specifically, we showed a trend for increased $\mathrm{p} 21^{\mathrm{Cip} 1}$ levels with tumour progression and that $\mathrm{p} 21^{\mathrm{Cip} 1}$ is potentially elevated in tumours with high nuclear cyclin D1 (Figure 5A and $\mathrm{C}$ ). These observations are consistent with observations in other tumour types (McKay et al, 2000; Holland et al, 2001; Tut et al, 2001) and support its role in promoting cyclin D1/CDK4 activity. Second, we showed that $\mathrm{p} 21^{\mathrm{Cip} 1}$ levels correlate with proliferation (Figure 5B), thus confirming other reports (Ljung et al, 1997; Baretton et al, 1999; Osman et al, 1999; Fizazi et al, 2002). Collectively, these data indicate that $\mathrm{p} 21^{\mathrm{Cip} 1}$ action in this tumour type likely favours proliferation. Similar conclusions about the role of $\mathrm{p} 21^{\mathrm{Cip} 1}$ have been seen in other tumour types such as breast cancer (Elledge and Allred, 1998). These studies indicate that $\mathrm{p} 21^{\mathrm{Cip} 1}$ is a likely effector of cyclin D1 accumulation, localisation, and activity in multiple tumour types, including prostate.

In summary, the data herein demonstrate that whereas cyclin D1 is generally elevated in localised prostate cancer, differential localization of cyclin D1 may influence clinicopathological parameters. The present data support a model wherein cyclin D1 accumulation and localisation are regulated as a function of tumour grade, and that differential cyclin D1 status significantly correlates with proliferation and PSA values. Further analyses revealed that $\mathrm{p} 21^{\mathrm{Cip} 1}$ may play a role in regulating cyclin $\mathrm{D} 1$ dynamics and likely contributes to the observed alterations in tumour characteristics. Together, these studies associated differential expression and localisation of cyclin D1 with important clinicopathological parameters and suggest new insight concerning the potential consequence of cyclin D1 induction in prostate cancer.

\section{ACKNOWLEDGEMENTS}

This work was supported by grant number CA 099996 (to K.E.K.).

\section{REFERENCES}

Aaltomaa S, Eskelinen M, Lipponen P (1999) Expression of cyclin A and D proteins in prostate cancer and their relation to clinicopathological variables and patient survival. Prostate 38: 175-182

Agus DB, Cordon-Cardo C, Fox W, Drobnjak M, Koff A, Golde DW et al. (1999) Prostate cancer cell cycle regulators: response to androgen withdrawal and development of androgen independence. J Natl Cancer Inst 91: 1869-1876

Alao JP, Gamble SC, Stavropoulou AV, Pomeranz KM, Lam EW, Coombes $\mathrm{RC}$ et al. (2006) The cyclin D1 proto-oncogene is sequestered in the cytoplasm of mammalian cancer cell lines. Mol Cancer 5: 7

Alt JR, Cleveland JL, Hannink M, Diehl JA (2000) Phosphorylationdependent regulation of cyclin D1 nuclear export and cyclin D1dependent cellular transformation. Genes Dev 14: 3102-3114
Alt JR, Gladden AB, Diehl JA (2002) p21(Cip1) Promotes cyclin D1 nuclear accumulation via direct inhibition of nuclear export. J Biol Chem 277: $8517-8523$

Arnold A, Papanikolaou A (2005) Cyclin D1 in breast cancer pathogenesis. J Clin Oncol 23: 4215-4224

Asatiani E, Gelmann EP (2005) Targeted therapies for prostate cancer. Expert Opin Ther Targets 9: 283-298

Balasenthil S, Sahin AA, Barnes CJ, Wang RA, Pestell RG, Vadlamudi RK et al. (2004) p21-activated kinase-1 signaling mediates cyclin D1 expression in mammary epithelial and cancer cells. J Biol Chem 279: $1422-1428$

Baretton GB, Klenk U, Diebold J, Schmeller N, Lohrs U (1999) Proliferation- and apoptosis-associated factors in advanced prostatic 
carcinomas before and after androgen deprivation therapy: prognostic significance of p21/WAF1/CIP1 expression. Br J Cancer 80: 546-555

Barr SM, Johnson EM (2001) Ras-induced colony formation and anchorage-independent growth inhibited by elevated expression of Puralpha in NIH3T3 cells. J Cell Biochem 81: 621-638

Bigoni R, Negrini M, Veronese ML, Cuneo A, Castoldi GL, Croce CM (1996) Characterization of $\mathrm{t}(11 ; 14)$ translocation in mantle cell lymphoma by fluorescent in situ hybridization. Oncogene 13: 797-802

Bubendorf L, Kononen J, Koivisto P, Schraml P, Moch H, Gasser TC et al. (1999) Survey of gene amplifications during prostate cancer progression by high-throughout fluorescence in situ hybridization on tissue microarrays. Cancer Res 59: 803-806

Buckley MF, Sweeney KJ, Hamilton JA, Sini RL, Manning DL, Nicholson RI et al. (1993) Expression and amplification of cyclin genes in human breast cancer. Oncogene 8: 2127-2133

Burd CJ, Morey LM, Knudsen KE (2006a) Androgen receptor corepressors and prostate cancer. Endocr Relat Cancer 13: 1-17

Burd CJ, Petre CE, Moghadam H, Wilson EM, Knudsen KE (2005) Cyclin $\mathrm{D} 1$ binding to the androgen receptor (AR) NH2-terminal domain inhibits activation function association and reveals dual roles for AR corepression. Mol Endocrinol 19: 607-620

Burd CJ, Petre CE, Morey LM, Wang Y, Revelo MP, Haiman CA et al. (2006b) Cyclin D1b variant influences prostate cancer growth through aberrant androgen receptor regulation. Proc Natl Acad Sci USA 103: $2190-2195$

Catalona WJ, Loeb S (2005) The PSA era is not over for prostate cancer. Eur Urol 48: $541-545$

Chen CD, Welsbie DS, Tran C, Baek SH, Chen R, Vessella R et al. (2004) Molecular determinants of resistance to antiandrogen therapy. Nat Med 10: $33-39$

Cheng M, Olivier P, Diehl JA, Fero M, Roussel MF, Roberts JM et al. (1999) The p21(Cip1) and p27(Kip1) CDK 'inhibitors' are essential activators of cyclin D-dependent kinases in murine fibroblasts. $E M B O \mathrm{~J}$ 18: $1571-1583$

Chhieng C, Cranor M, Lesser ME, Rosen PP (1998) Metaplastic carcinoma of the breast with osteocartilaginous heterologous elements. Am J Surg Pathol 22: 188 - 194

Coqueret O (2002) Linking cyclins to transcriptional control. Gene 299: $35-55$

Culhaci N, Sagol O, Karademir S, Astarcioglu H, Astarcioglu I, Soyturk M et al. (2005) Expression of transforming growth factor-beta-1 and p27Kip1 in pancreatic adenocarcinomas: relation with cell-cycleassociated proteins and clinicopathologic characteristics. BMC Cancer 5: 98

Dhar KK, Branigan K, Parkes J, Howells RE, Hand P, Musgrove C et al. (1999) Expression and subcellular localization of cyclin D1 protein in epithelial ovarian tumour cells. Br J Cancer 81: 1174-1181

Diehl JA, Cheng M, Roussel MF, Sherr CJ (1998) Glycogen synthase kinase3beta regulates cyclin D1 proteolysis and subcellular localization. Genes Dev 12: 3499-3511

Diehl JA, Sherr CJ (1997) A dominant-negative cyclin D1 mutant prevents nuclear import of cyclin-dependent kinase 4 (CDK4) and its phosphorylation by CDK-activating kinase. Mol Cell Biol 17: 7362 - 7374

Drobnjak M, Osman I, Scher HI, Fazzari M, Cordon-Cardo C (2000) Overexpression of cyclin D1 is associated with metastatic prostate cancer to bone. Clin Cancer Res 6: $1891-1895$

Dworakowska D, Jassem E, Jassem J, Boltze C, Wiedorn KH, Dworakowski $\mathrm{R}$ et al. (2005) Prognostic value of cyclin D1 overexpression in correlation with $\mathrm{pRb}$ and $\mathrm{p} 53$ status in non-small cell lung cancer (NSCLC). J Cancer Res Clin Oncol 131: 479-485

El Gedaily A, Bubendorf L, Willi N, Fu W, Richter J, Moch H et al. (2001) Discovery of new DNA amplification loci in prostate cancer by comparative genomic hybridization. Prostate 46: 184-190

Elledge RM, Allred DC (1998) Prognostic and predictive value of p53 and p21 in breast cancer. Breast Cancer Res Treat 52: 79-98

Epstein JI, Allsbrook Jr WC, Amin MB, Egevad LL (2006) Update on the Gleason grading system for prostate cancer: results of an international consensus conference of urologic pathologists. Adv Anat Pathol 13: $57-59$

Ewen ME, Lamb J (2004) The activities of cyclin D1 that drive tumorigenesis. Trends Mol Med 10: 158-162

Faglia G, Spada A (2001) Genesis of pituitary adenomas: state of the art. J Neurooncol 54: 95 - 110

Feldman BJ, Feldman D (2001) The development of androgen-independent prostate cancer. Nat Rev Cancer 1: 34-45
Fizazi K, Martinez LA, Sikes CR, Johnston DA, Stephens LC, McDonnell TJ et al. (2002) The association of $\mathrm{p} 21((\mathrm{WAF}-1 / \mathrm{CIP} 1))$ with progression to androgen-independent prostate cancer. Clin Cancer Res 8: 775-781

Fribourg AF, Knudsen KE, Strobeck MW, Lindhorst CM, Knudsen ES (2000) Differential requirements for ras and the retinoblastoma tumor suppressor protein in the androgen dependence of prostatic adenocarcinoma cells. Cell Growth Differ 11: 361-372

Fu M, Wang C, Li Z, Sakamaki T, Pestell RG (2004) Minireview: Cyclin D1: normal and abnormal functions. Endocrinology 145: 5439-5447

Gao W, Bohl CE, Dalton JT (2005) Chemistry and structural biology of androgen receptor. Chem Rev 105: 3352-3370

Germain D, Russell A, Thompson A, Hendley J (2000) Ubiquitination of free cyclin D1 is independent of phosphorylation on threonine 286. J Biol Chem 275: $12074-12079$

Gladden AB, Diehl JA (2005) Location, location, location: The role of cyclin D1 nuclear localization in cancer. J Cell Biochem

Gumbiner LM, Gumerlock PH, Mack PC, Chi SG, deVere White RW, Mohler JL et al. (1999) Overexpression of cyclin D1 is rare in human prostate carcinoma. Prostate 38: 40-45

Haag P, Bektic J, Bartsch G, Klocker H, Eder IE (2005) Androgen receptor down regulation by small interference RNA induces cell growth inhibition in androgen sensitive as well as in androgen independent prostate cancer cells. J Steroid Biochem Mol Biol

Han EK, Lim JT, Arber N, Rubin MA, Xing WQ, Weinstein IB (1998) Cyclin D1 expression in human prostate carcinoma cell lines and primary tumors. Prostate 35: $95-101$

Handa K, Yamakawa M, Takeda H, Kimura S, Takahashi T (1999) Expression of cell cycle markers in colorectal carcinoma: superiority of cyclin A as an indicator of poor prognosis. Int J Cancer 84: 225-233

Hibberts NA, Simpson DJ, Bicknell JE, Broome JC, Hoban PR, Clayton RN et al. (1999) Analysis of cyclin D1 (CCND1) allelic imbalance and overexpression in sporadic human pituitary tumors. Clin Cancer Res 5: $2133-2139$

Holland TA, Elder J, McCloud JM, Hall C, Deakin M, Fryer AA et al. (2001) Subcellular localisation of cyclin D1 protein in colorectal tumours is associated with p21(WAF1/CIP1) expression and correlates with patient survival. Int J Cancer 95: 302-306

Jemal A, Siegel R, Ward E, Murray T, Xu J, Smigal C et al. (2006) Cancer statistics, 2006. CA Cancer J Clin 56: 106-130

Jiang W, Zhang YJ, Kahn SM, Hollstein MC, Santella RM, Lu SH et al. (1993) Altered expression of the cyclin D1 and retinoblastoma genes in human esophageal cancer. Proc Natl Acad Sci USA 90: 9026-9030

Kallakury BV, Sheehan CE, Ambros RA, Fisher HA, Kaufman Jr RP, Ross JS (1997) The prognostic significance of $\mathrm{p} 34 \mathrm{cdc} 2$ and cyclin D1 protein expression in prostate adenocarcinoma. Cancer 80: $753-763$

Khor TO, Gul YA, Ithnin H, Seow HF (2006) A comparative study of the expression of Wnt-1, WISP-1, survivin and cyclin-D1 in colorectal carcinoma. Int J Colorectal Dis 21: 291-300

Knudsen KE, Arden KC, Cavenee WK (1998) Multiple G1 regulatory elements control the androgen-dependent proliferation of prostatic carcinoma cells. J Biol Chem 273: 20213-20222

Knudsen KE, Cavenee WK, Arden KC (1999) D-type cyclins complex with the androgen receptor and inhibit its transcriptional transactivation ability. Cancer Res 59: 2297-2301

Kolar Z, Murray PG, Scott K, Harrison A, Vojtesek B, Dusek J (2000) Relation of Bcl-2 expression to androgen receptor, p21WAF1/CIP1, and cyclin D1 status in prostate cancer. Mol Pathol 53: 15-18

Kuramochi J, Arai T, Ikeda S, Kumagai J, Uetake H, Sugihara K (2006) High Pin1 expression is associated with tumor progression in colorectal cancer. J Surg Oncol 94: 155-160

Lin HM, Zhao L, Cheng SY (2002) Cyclin D1 Is a Ligand-independent Corepressor for Thyroid Hormone Receptors. J Biol Chem 277: $28733-$ 28741

Lin X, Gelman IH (2002) Calmodulin and cyclin D anchoring sites on the Src-suppressed C kinase substrate, SSeCKS. Biochem Biophys Res Commun 290: $1368-1375$

Linja MJ, Porkka KP, Kang Z, Savinainen KJ, Janne OA, Tammela TL et al. (2004) Expression of androgen receptor coregulators in prostate cancer. Clin Cancer Res 10: $1032-1040$

Ljung G, Egevad L, Norberg M, Holmberg L, Nilsson S, Busch C (1997) Expression of $\mathrm{p} 21$ and mutant p53 gene products in residual prostatic tumor cells after radical radiotherapy. Prostate 32: 99-105

Lu F, Gladden AB, Diehl JA (2003) An alternatively spliced cyclin D1 isoform, cyclin D1b, is a nuclear oncogene. Cancer Res 63: 7056-7061 
Lu S, Liu M, Epner DE, Tsai SY, Tsai MJ (1999) Androgen regulation of the cyclin-dependent kinase inhibitor p21 gene through an androgen response element in the proximal promoter. Mol Endocrinol 13: 376-384

Lukas J, Bartkova J, Rohde M, Strauss M, Bartek J (1995) Cyclin D1 is dispensable for G1 control in retinoblastoma gene-deficient cells independently of cdk4 activity. Mol Cell Biol 15: 2600-2611

MacGrogan D, Bookstein R (1997) Tumour suppressor genes in prostate cancer. Semin Cancer Biol 8: 11-19

Majumder PK, Sellers WR (2005) Akt-regulated pathways in prostate cancer. Oncogene 24: $7465-7474$

Matsushima H, Sasaki T, Goto T, Hosaka Y, Homma Y, Kitamura T et al. (1998) Immunohistochemical study of p21WAF1 and p53 proteins in prostatic cancer and their prognostic significance. Hum Pathol 29: $778-783$

McKay JA, Douglas JJ, Ross VG, Curran S, Murray GI, Cassidy J et al. (2000) Cyclin D1 protein expression and gene polymorphism in colorectal cancer. Aberdeen Colorectal Initiative. Int J Cancer 88: 77-81

Mittnacht S (1998) Control of pRB phosphorylation. Curr Opin Genet Dev 8: $21-27$

Murphy C, McGurk M, Pettigrew J, Santinelli A, Mazzucchelli R, Johnston PG et al. (2005) Nonapical and cytoplasmic expression of interleukin-8, CXCR1, and CXCR2 correlates with cell proliferation and microvessel density in prostate cancer. Clin Cancer Res 11: 4117-4127

Nadal A, Cardesa A (2003) Molecular biology of laryngeal squamous cell carcinoma. Virchows Arch 442: 1-7

Omar EA, Behlouli H, Chevalier S, Aprikian AG (2001) Relationship of p21(WAF-I) protein expression with prognosis in advanced prostate cancer treated by androgen ablation. Prostate 49: $191-199$

Osman I, Drobnjak M, Fazzari M, Ferrara J, Scher HI, Cordon-Cardo C (1999) Inactivation of the p53 pathway in prostate cancer: impact on tumor progression. Clin Cancer Res 5: $2082-2088$

Palmqvist R, Stenling R, Oberg A, Landberg G (1998) Expression of cyclin D1 and retinoblastoma protein in colorectal cancer. Eur J Cancer 34: $1575-1581$

Parry D, Mahony D, Wills K, Lees E (1999) Cyclin D-CDK subunit arrangement is dependent on the availability of competing INK4 and p21 class inhibitors. Mol Cell Biol 19: 1775-1783

Petre-Draviam CE, Cook SL, Burd CJ, Marshall TW, Wetherill YB, Knudsen KE (2003) Specificity of cyclin D1 for androgen receptor regulation. Cancer Res 63: 4903-4913

Petre-Draviam CE, Williams EB, Burd CJ, Gladden A, Moghadam H, Meller $J$ et al. (2005) A central domain of cyclin D1 mediates nuclear receptor corepressor activity. Oncogene 24: 431-444

Radu A, Neubauer V, Akagi T, Hanafusa H, Georgescu MM (2003) PTEN induces cell cycle arrest by decreasing the level and nuclear localization of cyclin D1. Mol Cell Biol 23: 6139-6149
Reutens AT, Fu M, Wang C, Albanese C, McPhaul MJ, Sun Z et al. (2001) Cyclin D1 binds the androgen receptor and regulates hormonedependent signaling in a p300/CBP-associated factor (P/CAF)-dependent manner. Mol Endocrinol 15: 797-811

Rigaud J, Tiguert R, Decobert M, Hovington H, LaTulippe E, Laverdiere J et al. (2004) Expression of p21 cell cycle protein is an independent predictor of response to salvage radiotherapy after radical prostatectomy. Prostate 58: $269-276$

Sarkar FH, Li Y, Sakr WA, Grignon DJ, Madan SS, Wood Jr DP et al. (1999) Relationship of p21(WAF1) expression with disease-free survival and biochemical recurrence in prostate adenocarcinomas (PCa). Prostate 40: $256-260$

Sato Y, Itoh F, Hareyama M, Satoh M, Hinoda Y, Seto M et al. (1999) Association of cyclin D1 expression with factors correlated with tumor progression in human hepatocellular carcinoma. J Gastroenterol 34: $486-493$

Sherr CJ, Roberts JM (2004) Living with or without cyclins and cyclindependent kinases. Genes Dev 18: 2699-2711

Simpson DJ, Frost SJ, Bicknell JE, Broome JC, McNicol AM, Clayton RN et al. (2001) Aberrant expression of $G(1) / S$ regulators is a frequent event in sporadic pituitary adenomas. Carcinogenesis 22: 1149-1154

Sonpavde G, Hutson TE, Berry WR (2006) Hormone refractory prostate cancer: management and advances. Cancer Treat Rev 32: $90-100$

Sudo T, Irie A, Ishii D, Satoh E, Mitomi H, Baba S (2003) Histopathologic and biologic characteristics of a transitional cell carcinoma with inverted papilloma-like endophytic growth pattern. Urology 61: 837

Sumrejkanchanakij P, Eto K, Ikeda MA (2006) Cytoplasmic sequestration of cyclin D1 associated with cell cycle withdrawal of neuroblastoma cells. Biochem Biophys Res Commun 340: 302-308

Taplin ME, Balk SP (2004) Androgen receptor: a key molecule in the progression of prostate cancer to hormone independence. J Cell Biochem 91: $483-490$

Temmim L, Ebraheem AK, Baker H, Sinowatz F (2006) Cyclin D1 protein expression in human thyroid gland and thyroid cancer. Anat Histol Embryol 35: 125-129

Tetsu O, McCormick F (1999) Beta-catenin regulates expression of cyclin D1 in colon carcinoma cells. Nature 398: $422-426$

Trapman J (2001) Molecular mechanisms of prostate cancer. Eur J Cancer 37(Suppl 7): S119-S125

Tut VM, Braithwaite KL, Angus B, Neal DE, Lunec J, Mellon JK (2001) Cyclin D1 expression in transitional cell carcinoma of the bladder: correlation with p53, waf1, pRb and Ki67. Br J Cancer 84: 270-275

Xu Y, Chen SY, Ross KN, Balk SP (2006) Androgens Induce Prostate Cancer Cell Proliferation through Mammalian Target of Rapamycin Activation and Post-transcriptional Increases in Cyclin D Proteins. Cancer Res 66: $7783-7792$ 